\title{
Chapter 6 \\ Dialogical Engagement and the Co-Creation of Cultures of Exploration
}

\author{
Elin Eriksen Ødegaard
}

\subsection{Introduction}

A continuous inquiry exists regarding how the older generation can best create conditions for children to survive and live good, responsible lives. Cultures and nations have had shifting ideas and ideals for how to introduce children to the cultures in which they live and how to regulate education. Cultural traditions are the foundational drive that is expressed when societies govern educational processes, shape the conditions for life experiences and support or hinder dialogue and 'bridge-building' between persons, whether intentionally or not. There is an interdependence and organic relationship between cultures and education, but changing conditions at a personal, local, societal and global level also drives individuals and communities to explore, discover, create and, thereby, drive change. Both children and adults, through living with others, are shaped by the organic interplay with the local culture: nature, landscapes, materiality, discourses, relations and societies.

This chapter will outline a new culturally and worldly sensitive pedagogy that is relevant for children for their everyday lives and, hopefully, for their future. The aim is to argue for, discuss and outline conditions for a pedagogy that promote exploration and how they contribute to children's cultural formation in the complex context of early childhood education and with hope for a sustainable future. The conditions and characteristics of explorative practices, found in earlier literature and experiences, interact in dynamic ways and are therefore difficult to grasp. Central to the chapter is the attempt to visualise how characteristics of explorative practices interact with some central conditions in local settings. A model for children's exploration as dialogical engagement is formulated. Moreover, a setup of binary pairs of

\footnotetext{
E. Eriksen Ødegaard $(\bowtie)$

Faculty of Education, Arts \& Sports, Western Norway University of Applied Sciences,

Bergen, Norway

e-mail: elin.eriksen.odegaard@hvl.no
} 
educational cultures, principles and practices is presented to answer a curiosity about what the characteristics in cultures of exploration will be. By such a setup, the importance of pedagogical dialogical engagement is highlighted. This model could serve as an analytical tool in analysing pedagogical practices and discourses where children and teachers are, or attempt to be, explorative and sensitive to problems, relationships, signs and sensations when working and playing together.

In this chapter I will outline and discuss a pedagogical model that can serve as a thinking tool and as a means to move away from unsustainability within a broad cultural-historical and sustainability framework. The framework includes both social and environmental dimensions, in which space, as well as global and local concerns, is considered in a pedagogy that is relevant for teachers, children and families today for active citizenship that values diversity and the survival of nature.

\subsection{Cultural-Historical Perspective and Ecological Inspiration}

The chapter is first and foremost anchored in a cultural-historical approach, drawing on, among others, dialogism and concepts like heteroglossia, speech genres and Mikhail Bakhtin's loophole. The chapter argues that dialogism is central to cultures of exploration. The term 'dialogism' is most commonly used to mean the quality of an example of discourse that is defined by its relationship to other instances, both past, to which it responds, and future, whose response it anticipates (Shephard, 2013). The positive connotations of dialogism are often reinforced by a contrast with 'monologism', which in pedagogy refers to the refusal of authoritative discourse. 'Dialogism' refers to the literary work of Mikhail Bakhtin and the Bakhtin circle and to the diversity of socially specific discourses (heteroglossic, carnival and the multivocal analytic approach) in research as well as in pedagogy inspired by Bakhtin's work. In pedagogy this implies the role of a teacher who orchestrates the diverse voices in a classroom and raises awareness of how cultural expressions wander and how spoken and bodily language, positions and performative actions are linked through time and place.

Also, Seth Chaiklin and Mariane Hedegaard's arguments and ideas for a radical local pedagogical approach (2005) are a thinking tool for creating awareness of the local and the global in framing and recognising children's experiences, and they are set out in order to argue for a respectful exchange when considering the content and values of the 'what' in exploration. The professional teacher will always have an official mandate (e.g. curriculum or framework) and a personal ethos and drive when meeting, taking up and further building upon children's initiatives. This is how the local content can develop within 'frames of frameworks'. Through examples, I will illustrate how a pedagogy for explorative practices will always have 'something worth exploring', such as a content, a third space, which will be further developed in this book (e.g. Eikset \& Ødegaard). Cultures of exploration in early childhood education introduce a promise of a pedagogy where the teacher co-creates 
kindergarten content when operating in practice, in planning and meeting children and families in their local community and in considering activities, relations, place and space. Discourses on early childhood education (ECE) can be roughly constructed as follows:

1. Child-centred: highlighting what goes on in institutional practices 'here and now', often concentrated around 'play' and 'children's participation'. Childhood and the recognition of its value 'in its own right' - not only as a waiting periodis an underlying value.

2. Teacher-centred: highlighting didactic aspects and children's learning in education. It can also be research-focused regarding conditions for children's play, learning, care and formative development. The aims will often be higher-quality education.

3. Complexity- and micro-centred: focusing on conditions for pedagogical practices, often highlighting the plurality and interconnectedness of children and teachers' practices. It explores how bridges are connected from the material to social and 'common worlds' outside the walls of a kindergarten and how things intersect. The aims will often be of a critical nature or be related to disclosure; however, it also aims to combine more perspectives to gain new insight on relevance for pedagogy and education.

The research position underlying the model suggested in this chapter is within the last category: the complexity and micro-centred discourse. I agree with researchers who suggest that it is timely to decentre children's voices as only unique and genuine and childhood as a protected period with romanticised connotations, as also discussed in childhood studies (Alanen, 2009; Kjørholt, 2004), early childhood and cultural-historical studies (Chaiklin \& Hedegaard, 2013; Matusov, 2009; Ødegaard, 2007; Rogoff, 2003; Samuelsson, Kultti \& Pramling, 2018) and ecological and 'non-human' - 'more-then-human' studies (Braidotti \& Bignall, 2019; Ingold, 2011; Pacini-Ketchabaw, 2017; Spyros, 2017).

\subsection{A 'Glocal' Awareness and Moving Away from Unsustainability}

As children today live complex situational local lives, and as the pedagogical mandate for the professional teacher within early childhood settings will need to consider the best interest of all children, local and micro-orientations as well as 'glocal' awareness is necessary. 'Glocal' conceptualises the idea that globalisation does not necessarily penetrate every aspect of the local culture, traditions and views. Despite globalisation, local conditions can be adopted, held on to and transformed to something beyond what was there beforehand. As already stated in the introduction to this book, it was Roland Robertson (1995) that introduced the concept of 'glocalisation' in his classic Glocalization: time-space and homogeneity-heterogeneity, 
where he comments on the assumption that globalisation refers to a large-scale phenomenon and that what one thinks of as local is in fact constructed in a trans-local setting and will often occur in a large-scale locality. He also advises against the taken-for-granted view that globality is a consequence of modernity, as what we call modernity has developed historically in different places without any direct connection between them. Roland Robertson (1995) critiques the polarised concept of the global and the local and instead invites the reader to a more dynamic understanding of them.

For my agenda here, I will present an example to illustrate the connections. On Earth, we now experience warmer, wetter and wilder weather in the local land where I live, and it is common knowledge that these weather events are due to global warming and environmental changes. In the autumn of 2018, on the west coast of Norway, where kindergartens are situated under mountains and in narrow valleys, roads and schools were closed down due to flooding. Heavy rain created new waterfalls in places where waterfalls had never existed. Children were evacuated while a heavy stream of water found new ways into the playground within minutes, and the inside of the kindergarten building rapidly filled with water. Suddenly, what we called 'everyday practices' were disrupted by critical events and emergencies.

Climate change impacts children's lives every day, whether it be through the sun that dries out the soil and makes growing and maintaining water supplies difficult or through extreme storms that destroy families' homes and roads to schools and kindergartens.

A 'glocal' place awareness can frame pedagogy within the larger boundaries of sustainability or aim for practices towards sustainable futures. This will require a teacher's eye for pedagogical practices concerning local landscapes, places and weather systems (Ingold, 2018; Myrstad \& Sverdrup, 2016; Ødegaard \& Marandon, 2018). Curricula will need to address core conditions for survival from a general attention to well-being and to responsiveness for emergencies and crises (Liu \& Liu, 2008). As part of a professional responsibility, we need to understand the structural systems that operate at a societal level, and be able to analyse and reflect on our own biases and prejudices and habits (Nolet, 2017). What happens when habits and knowledge are disrupted, and professional judgment must operate on an immediate impulse or aim for a future-oriented new professionalism? What are the concerns in the best interest of the child? What matters for children from a perspective of wellbeing and generational survival? What skills are the most important to learn? Will they be critical and creative digital and media skills or academic reading, writing and mathematics, or will the most important skill be of another kind? Activities such as digging, pulling, building, knitting, sewing, sawing, composting, deconstructing and reconstructing historically belong to everyday life, handicraft and work life.

For example, when the teacher takes on an indigenous viewpoint, a 'more-thanhuman' pantheistic way of knowing, being and acting can easily be actualised. Even if this is not the case for all persons with an indigenous identity, the first principle of the Treaty binding the United League of Indigenous Nations (2007) proclaims that humans are part of, and inseparable from, the natural world and that this gives rise to a shared commitment to care for, conserve and protect the land, air, water and 
animal life where they live. The standardisation of knowledge and ways of learning will easily carry the risk of violation towards local values and heritage (Fuller, 2007) as well as children's initiatives (Sandvik, 2012). My argument is that sustainability has an obvious cultural dimension that actualises a wide range of important content areas relevant for early childhood education, such as local heritage, arts, the diversity of nature, the internet and indigenous culture, among others, as well as the pedagogical practices actualising a wide range of important content areas. The cultural and creative dimensions of sustainability need to be given more attention. My argument will be that a pedagogy that opens the floor for explorative practices within a frame of values will support sustainable futures in contrast to a standardised curriculum with a strong teacher-centred approach will easily be blind and ignorant to local culture and lead to 'unsustainability'. Also, a strong child-centred 'here and now' approach can be unsustainable, as it leaves too much responsibility to the children alone and ignores the value of generational knowledge and responsibility. To make change that aims for sustainable futures, it will be necessary to work against unsustainability, in which children's everyday lives and needs are not valued, followed up or maintained, because unsustainability can destroy relationships, be harmful to people and it will eventually be empty or could jeopardise humankind and the planet in the long run. A wider understanding about culture is also need in order to analyse and understand how societal structures as well as environmental dynamics work out (Fleer, Hedegaard, \& Tudge, 2009).

One way to work against unsustainability is, in my opinion, to elicit the role of the teacher with the above-mentioned inspiration. According to Jayne White (2016), dialogic pedagogy in the early years shifts the emphasis of the teacher from a facilitator of an external curriculum, activity or project to one of a partner, co-learner, investigator and provocateur (p. 65). I will in the following section turn to the concept of exploration and a model considering dialogical engagement as the key teachers' approach in the early years. I will add to that approach inspirations from ideas of holism, 'glocalisation' and the 'wayfarer' as a model of the teacher, addressing a worldview of sustainable futures into education (e.g. Ingold, 2011; Ødegaard, 2015, 2018a).

\subsection{A Pedagogical Model of Exploration as Dialogical Engagement}

Today, exploration is a concept seen in recent ECE frameworks, such as the Norwegian Framework Plan for Kindergarten Content and Tasks (Ministry of Education and Research, 2017). This framework plan states, 'Through interaction, dialogue, playing and exploring (my emphasis), the children shall have the opportunity to develop critical thinking, ethical judgment, ability to resist and action competence so that they can contribute to changes' (p. 8). The concept of exploration entails a dynamic process and a positive verb. The concept is also mentioned in the 
framework plan to perceive children as agents who make sense of the world and learn. In this framework, exploration is regarded as a crucial, complex practice-a wheel for play, learning and participation (i.e. agency). The concept of exploration can be etymologically traced to the meaning of investigation and examination (Harper, 2001-2012). Explore is derived from the Latin explorare, which entered the English language around the fifteenth century (Lawrence, 2010).

The concept of exploration can be said to refer to a play- or curiosity-related action, a social situation that affects what and how objects and relations are explored. However, exploration, as a concept, can also be differentiated from play and curiosity, but never with clear distinctions. In the past, literature has often conceptualised 'exploration' as a fixed sequence of behaviours with relatively stereotyped patterns across situations and species, as well as an open concept proceeding curiosity and play (Schoggen \& Schoggen, 1985, p. 78). Exploration and curiosity are close in definition, as both imply seeking information and initiating behaviour and can therefore be seen as proceeding play as well as being central for play activities to be developed and sustained.

In my inquiries ${ }^{1}$ into understanding what exploration is and what it means for children's meaning-making and development, I have been searching for the characteristics and how such a concept and activities relates to similar concepts and practices such as creativity, improvisation and open-ended dialogue, and I have found examples of literature reviews relevant for understanding exploration and the distinctions between close concepts (Schoggen \& Schoggen, 1985; Sawyer, 1997, 2011a, 2011b).

A dialogical understanding of culture as dynamic required a figure that could illustrate movements and a complex set of conditions for exploration and its characteristics. The shape of what could be a loop, a halfway loophole or a spoon was chosen to indicate dynamics, movement, process and change. The metaphor of the loop is inspired by Michael Bakhtin's writings ${ }^{2}$ (1973) about loopholes. He writes with reference to loopholes taken by the hero in a novel: //... "altering the final meaning of one's words, as a side glance or a shift of focus. //... The loophole makes the hero ambiguous and elusive even for himself. In order to break through to his self the hero must travel a very long road (Bakhtin, 1973, pp. 233-34)". This metaphor of a loophole can indicate the moves and manoeuvres, the 'journey', it can take for the professional teacher to learn from what happens in events. Whether it is an emergent feeling, a motivation to listen, a long-term transformative experience or a sudden understanding, the metaphor signifies the possibility for a teacher to adjust to the multitude of voices and events taking place in an early-year setting. A loop is the aesthetic shape of a movement, a change or a point of professional learning, becoming a self-reflexive professional in the ongoing co-explorative activities and

\footnotetext{
${ }^{1}$ The research group 'Kindergarten as an arena for cultural formation' at Western Norway University of Applied Sciences has for many years worked together on understanding, conceptualising and operationalising the concepts and practices of exploration and cultural formation. I will acknowledge the dialogue in the research group.

${ }^{2} \mathrm{He}$ analyses the novels of Dostoevsky (Bakhtin, 1973).
} 
events. A potential other meaning and discovery is visualised by the shape of an open loop.

The model has the shape of a halfway loophole that contains a layer of key dynamics conditioning exploration, and at far left, at what is the end or the starting point, there is a handle to set off or end the dialogical engagement, or taking on a discourse, a specific genre of pedagogical performance that carries the possibility of change. The main drives and triggers for explorative performance in education are the body, experiences and conditions from sensations, movements, artefacts, materiality and symbols. Inside the loop there is a division between, on the left-hand side, the key notions to indicate where exploration takes place and, on the righthand side, the characteristics of explorative activities. The shape of the model illustrates a pedagogical drive, an urge, with engagement, to understand the space in which children live, to move dialogically in order to take up children's initiatives and to support and ensure that children's right to participation in their own life is realised within a value frame of generational responsibility. As such, it is an idealistic model for the wider context of sustainable futures, meant to illustrate some crucial dynamics, drives and key notions for realising exploration, a pedagogical practice that allows multiple ways of knowledge. The importance of the teachers' engagement and the close relationship between nature and a holistic play-driven pedagogy was evident through literature from early on in educational history (e.g. Comenius, 2012; Fröbel, 2012 [1861]; for further reading, see chapter Eikset \& Ødegaard in this book and Ødegaard, 2018b) (Fig. 6.1).

In the following section, I will describe the composition of the model in attempts to theorise exploration as dialogical engagement. Being dialogical means, according to Michael Holquist (1990, p. 21), that reality is always experienced. Being (as

\section{Exploration as dialogical engagement}

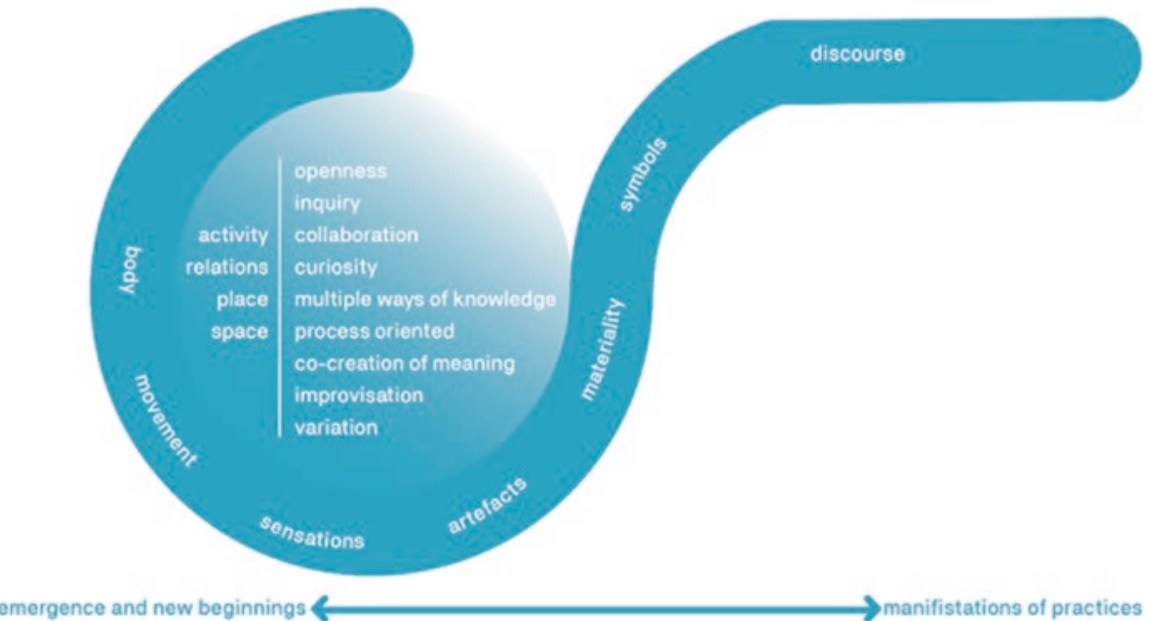

Fig. 6.1 Exploration as dialogical engagement 
in being alive) is simultaneous: it is always a co-being, which means that when I write 'teacher', it always implies the 'child', and vice versa. This means that the situatedness of the teacher is a multiple phenomenon; the task is not just given, but there is a 'drive for meaning', where meaning is understood as still being in the process of creation (p. 24). However, what is experienced from a particular position. Bakhtin has formulated this as the 'Law of Placement' (Holquist, 1990). This is a concept referring to the unique spatiotemporal coordinates we live in. A perception can only be achieved from a unique point in the spectrum of possibilities. This also then means that an event and an activity will always be perceived differently, even if being alive is simultaneously living and co-existing.

Bakhtin uses 'person' as synonym for 'self', and the person will have a voice. According to Bakhtin, this voice is not a unique voice, but a voice embedded with historical voices. Meaning is viewed as an emergent phenomenon, integrating aspects of the immediate, the social and the historical context of performance (Bostad, Brarndist, Evensen \& Faber, 2004, p. 2). This is expressed in the model by a timeline.

\subsection{Time—Emergence and Manifestations of Practice}

The model consists of a timeline in order to illustrate the inevitability of time and process as fundamental in pedagogy. The emergence, the possibilities that lie in new and vague attempts (Sawyer, 1997), needs to be central in pedagogical frameworks where participation and democracy are the wider goals and values. At the same time, a professional pedagogical practice cannot only be in the vague beginnings. Manifestations and concretisations of ideas and initiatives must be followed up and developed in professional practice. The model therefore consists of a timeline from emergence to manifestations to highlight that explorative activities are practices where process, such as time, is central. The model visualises how cultures of explorations need to consider time. Time is both the here and now and the future (i.e. being and becoming); it is, at the same time, connected to the physical and social worlds. Becoming indicates 'changing to', 'moving towards' and 'formative development' and actualises the life history of persons, artefacts and signs and what that means for pedagogy. Temporality in the thinking of children and childhood contributes to more nuanced understandings of children and their future lives.

Being a child and becoming a child, as well as the process of practising as a teacher, will inevitably imply a manifestation of time and place (i.e. chronos and topos); being is constantly also becoming. Being a child is not a static position (i.e. stagnation) but rather a condition of movement in the social and physical spaces made available for children (Uprichard, 2008). Becoming, therefore, does not need to be understood in the context of a long time span needed to mature but as constantly generating practices (Borgen \& Ødegaard, 2015, p. 10). Becoming conceptualises the constant temporal movement, which is also visualised in the model presented later in this chapter. A discursive creation of a dichotomy of being and 
becoming is, therefore, not a productive one. In addition to the dimension of time, explorative activities will always be situated in space. In the model, space is a key word in line with activity, relations and place to illustrate how they operate in fluidity with the more specific spectrum of practices of exploration.

\subsection{Characteristics of Exploration in Pedagogy}

When searching for an understanding of exploration, it can be productive to look for negations. There are many similar notions to exploration, some more overlapping than others. To ask, 'What is exploration not'? in an educational setting might help to clarify and make distinctions between exploration as a concept and a particular activity and practices characterised by exploration. In a Bakhtinian framework, a possible way of anchoring the model can be as a speech genre ${ }^{3}$ (Bakhtin, 1986), but the characteristics of exploration in early childhood pedagogy go beyond the spoken word, so the understanding of a speech genre must include speech as body (Linnell, 2009). Exploration practices can be verbal, silent practices, driven by body, performance and doings. In a study on people with hearing impairments and vision loss, Per Linnell describes how they orient themselves in the material, sensational and symbolic world (2009). This study gives a relevant reminder for early childhood research and pedagogy. Whether it be words uttered or bodily senses expressed, each perception must be understood as a link in a complex chain of other expressions.

Oliver Escobar (2009) offers, from a post-empiristic ${ }^{4}$ and dialogic ${ }^{5}$ orientation, a synthesis of contrasts between adversarial (i.e. argumentative) and dialogic communication (p. 55). Escobar's research fields are policy studies and democracy; however, key principles are productive for digging into understanding the conditions for exploration in an ECE setting. With inspiration from Escobar, I will reconstruct and add some relevant dichotomies in order to make it clearer what pedagogical principles and practices we are talking about when discussing exploration and what kinds of pedagogical cultures and practices might support exploration within the field of ECE.

Table 6.1 Contrasts Between Monologic and Dialogic Educational Cultures' Principles and Practices offers an overview of some key contrasts between the discursive practices ${ }^{6}$ of adversarial and dialogic communication.

\footnotetext{
${ }^{3}$ Bakhtin (1986) critiqued the way Ferdinand Saussure understood language as words and sentences, ignoring the cultural historical subsystems of language. A speech genre is a precondition for understanding communication in meaningful ways, as it organises the speech in similar ways, in style, structure and content.

${ }^{4}$ The rejection of strict empirical methods as seen by modern empiricists. Post-empirists are also post-positivist.

${ }^{5}$ The most influential thinkers in this orientation have included Mikhail Bakhtin, Martin Buber, George Herbert Mead and Paulo Freire.

${ }^{6}$ What Escobar calls adversarial, I will articulate as monologic after Mikhail Bakhtin (1981), since Bakhtin already has a range of concepts well-suited for understanding pedagogical principles and practices.
} 
Table 6.1 Contrasts Between Monologic and Dialogic Educational Cultures' Principles and Practices

\begin{tabular}{l|l}
\hline Monologic educational culture & Dialogic educational culture \\
\hline Rules and regulations & Inquiry \\
\hline $\begin{array}{l}\text { Cultural mode of certainty and } \\
\text { stability }\end{array}$ & Cultural mode of uncertainty and negotiation \\
\hline Confrontational & Collaborative \\
\hline Emphasis on performance & Emphasis on relationships \\
\hline Outcome-oriented & Process-oriented \\
\hline Communication as transmission & Communication as dialogue \\
\hline Expertise as superior knowledge & Expertise as polyvocality \\
\hline Ignoring some soft forms of & Embracing multiple forms of knowledge \\
\hline knowledge & Show, tell, follow up and create new elements \\
\hline Transfer of culture & Cultures of transformation \\
\hline Show and tell & Co-creation of meaning \\
\hline Persuasion & Creating spaces for participation \\
\hline Argumentation for one way & Cultures of dialogue \\
\hline Cultures of dominance & Creativity and improvisation \\
\hline Framing & $\begin{array}{l}\text { Attempts to discover new combinations, new transfer, new } \\
\text { methods and solutions }\end{array}$ \\
\hline Attempts to narrow and specify & Cultures of opening \\
\hline Cultures of closing & Variation \\
\hline Uniformity & Attempts to widen perspectives, giving new experiences \\
\hline Attempts to standardise & Cultures of difference as a resource \\
\hline Cultures of one size fits all &
\end{tabular}

In Table 6.1, I have displayed characteristics and practices of educational cultures set up as dichotomies (i.e. monologist versus dialogic). The concepts from this table are chosen to indicate the core characteristics of exploration as dialogical engagement, as illustrated inside the loop of the model. The principles and practices presented here will be ideal types; in real life, these two orientations will often comprise hybrids in complex communication. The role of the teacher will be different in these two binaries. In the monologist culture of education, the teacher will be merely a judge or referential organiser. In the dialogic culture, the teacher is merely a guide and participant. According to Bakhtin (1981), we do not communicate in a vacuum; rather, we will always exist in response to things that have been said before and in anticipation of things that will be said in the future. Monologic refers to a principle and practice where a single person or organisation is dominating or monopolising a conversation or discourse, while dialogic culture refers to the understanding of communication as always being in relation to something else (Bakhtin, 1981; Nesaria, 2015). Educational dialogic cultures can be set up as dichotomies on the theoretical level. Real-life situations will most likely have elements of both, but it is 
also likely that they will exhibit dominant patterns of either monologist or dialogic practices.

In this section, I will further highlight one of the key words, improvisation, in order to give a deeper sense of the overlap with exploration and illustrate how this key word relates to time, emergence and manifestations at the bottom of the model. Keith R. Sawyer's (1997) innovative work on understanding improvisation is relevant to the attempt to elaborate on exploration. In his effort to describe improvisation, Sawyer also uses the term emergent to describe how children improvise in play. According to Sawyer, the emergent will often be heteroglossic ${ }^{7}$ (Bakhtin, 1981) because each child participating will have a slightly different understanding of the play frame (Sawyer, 1997, p. 48). The emergent will also contain the sociorelational dynamics resulting from the flow of the play drama and will be regulated by the continual change during the play process. Improvisation is, as such, not a synonym for exploration; rather, while improvisation will contain fantasy and variations, exploration is a wider concept that embraces improvisation. Both concepts imply time-historical, present moment and future time- as emergence unfolds in time. In order to understand exploration as a process, the emergent will open up for understanding exploration as a movement that will eventually manifest and that can be observed and acted upon. The emergent, a time span in a flow of interaction, will supplant understandings of exploration as a concept belonging to research and pedagogy. The manifestations will be moments to grasp. In pedagogy, as in research, it will not be possible to grasp every aspect of the complex nature of institutional life at once. The model can offer a simplification, with suggested manifestations relevant for understanding exploration.

\subsection{Activity, Relations, Place and Space}

Human activity takes 'place' in 'space'. When activities are planned for, carried out and evaluated in the curricular context of early childhood, they are situated in space, at a certain place. Activities are the obvious manifestations, but climate change affects food supplies, shelters and new migrant patterns. Local environments, such as urban city landscapes as well as rural agricultural, mountainous and water landscapes are the world of the child as well as the teacher. These thoughts represent an 'outwardlookingness' (Nairn, Kraftl \& Skelton, 2016, p. 6) that considers geographies. Geographies are also considered at an activity level by Marilyn Fleer and Mariane Hedegaard (2010) to illustrate how, in a case study from a Peninsula family, children had rapid movements from room to room to ensure that they could take part in events. Adults also had this 'roaming behaviour' ('geographical roaming' [p.

\footnotetext{
${ }^{7}$ Bakhtin (1986) argues that heteroglossia (in the novel) means the coexistence of, and conflict between, different types of speech: the speech of characters, the speech of narrators and the speech of the author. He defines heteroglossia as 'another's speech in another's language, serving to express authorial intentions but in a refracted way' (Holquist, 2002).
} 
12-14]), moving around as participation in everyday life events and activities. Such a geographical roaming can also be articulated as spatial meaning-making. In pedagogy, an awareness of the cultural dimension of spatial meaning-making creates an understanding of children's bodies and movements in a more resourceful way than in linear education, where the task of the teacher is to create cultures for listening and disciplining the body for sitting down in teacher-directed activities.

Space, in its most fundamental forms, relates to the surfaces and volumes of earth (Nairn et al. 2016), and it is of high actuality for early childhood pedagogy in times where posthuman ecologies challenge the 'human only'-centred paradigms (Braidotti \& Bignall, 2019).

Space is also a notion of interest in pedagogy as a metaphor: 'participatory agentic space', which represents the curricular space in which children can move and act in flux with the ecological frames of institutions (Ødegaard, 2007). Children in kindergarten may have a 'participatory agentic space'; nevertheless, it will be a regulated space within the systems, structures and control of the curriculum and the teacher. The curricular space contains the activities and everyday practice made available to them. A teacher that will plan for activities must consider that an activity is set in certain locations and that those locations will constitute one of the many dynamics and conditions.

Place refers to the local and the global and bears the possibility of encouragement and engagement with the decolonising pedagogy in diverse early childhood settings. Children and teachers will always be situated locally in place. Children can sometimes have their own territorial places but will nevertheless, most of the time, spend time in shared localities in families as well as in institutions. A dynamic understanding of place (Fleer \& Hedegaard, 2010; Massey, 1991, 2005; Tobin, Hsueh \& Karasawa, 2009) enables the teachers to ask and search for understandings of what place, local or global, means for children and families and, through that, answer accordingly with sensitivity. Thinking with place actualises a 'glocal' curriculum. Such a curriculum is inevitable wherever we live, but it can be silenced through education. A high awareness of the co-existence of the global and the local is necessary in pedagogy, along with the concept of space, because children who are born today are beginning their lives in the Anthropocene ${ }^{8}$ age (Steffen et al., 2011; Ødegaard \& Marandon, 2018). Natural and material forces and human forces are seen as intertwined and interdependent, and they play out locally.

An important dynamic condition for exploration as dialogical engagement is relations. Relations embrace both the interpersonal dialogue and activities and the relations to the conditions mentioned in the curve in the model. In the following section, I will elaborate on how dialogical relations are fundamental in pedagogy that is characterised by exploration as dialogical engagement, as illustrated inside the loop in the model.

\footnotetext{
${ }^{8}$ The age of the Anthropocene was proposed in 2000 as a new phase in the history of humankind and of the Earth. Academics (Capra, 1982; Kagan, 2013) and the Intergovernmental Panel on Climate Change (Lee, 2018) agree that the world is close to a tipping point and that humans have had a damaging impact on planetary processes.
} 


\subsection{Illustrations and Discussions of Conditions}

The last element in the model is the key concepts that indicate human and nonhuman conditions. In real life there will be a wide spectrum of conditions for explorative pedagogy. The model picks up on some selected conditions, such as body, sensation, movement, artefacts, materiality and symbols, all of which are examples of conditions that constitute entangled complexities handled in dialogical engagement. In the model, these concepts are placed in the layer with the shape of the halfway loop to indicate that these are the main drivers and triggers for explorative performance in education.

In the following section, I will give examples and discuss these and more complex conditions to elaborate on these bodily, material and discursive conditions.

The core point in this effort of presenting a model of exploration as dialogical engagement is an interest in children's exploration and meaning-making processes - in how children shape themselves and are being shaped in a dynamic wave, where personal, structural and discursive conditions operate in a flux. The philosophy of dialogism implies an approach to understanding culture as a living tradition. Culture, as a concept, is open, like 'art' and 'play', and needs Culture an articulated perspective. I view culture dialogically, implying that culture has ethical, epistemological and aesthetic dimensions. Culture is embodied, central to meaning-making and a core matter for everyone (Bostad et al. 2004).

The process of a person's self-formation-the constantly changing state of becoming a person-will always be conditioned. When persons are agentic and manoeuvre in their own lives, they are always acting in relation to someone, something and somewhere, which in turn shapes the conditions of what is possible to act upon, how to act and when.

In addition, places and artefacts-whether material or intellectual-will offer something to the exploration. One example is the descriptive study of two teacherresearchers exploring mathematical artefacts with children in an early years institutional setting (Pettersen, Volden, \& Ødegaard, 2016). Besides the descriptions of how children explored the mathematical materials and a corresponding model on a tablet, the pedagogical findings demonstrate how the researchers as teachers and young children's activities can be driven by curiosity and a motive or drive to make meaning and to explore. Of special interest to the researchers as teachers was the children's surprisingly deep interest in the activity. Some children were deeply engaged for hours, while other children went in and out of the activity. The researchers suggest three main characteristics of the activities that might explain the deep explorative involvement. First, the activity was open-ended in time. Second, it was introduced as a shared, voluntary activity. Third, it introduced tangible artefacts (i.e. material bricks and shapes) and changeable artefacts (i.e. a tablet with models and applications). The activity was staged on the floor, which supported the open-ended character of the activity, and the researchers as teachers were engaged with the children, which demonstrated cooperation and co-creation. This description illustrates some core aspects highlighted in the model of exploration as dialogical engagement. 
How signs and discourse constitute conditions for cultural formation and explorative practices can be illustrated by a comparative study of semiotic landscapes. In an analysis of the discursive conditions for teachers' linguistic practice with multilingual children in Norway and Germany, Anja Pesch (2017) used Bakhtinian concepts of utterance, speech genres, voice, discourse and ideology. She found that, even if the ECE in both countries viewed multilingualism as a resource in verbal communication, the staff in the German kindergarten held a more dynamic view of multilingualism, and a multilinguistic practice was observedin the early years' institution. By studying the semiotic landscapes, Pesch observed, that while the Norwegian kindergartens related their semiotic landscapes to national identity (e.g. flags), such national signs were absent in the diverse German kindergartens, because people's national identities are sensitive and were not found to be relevant in the German context. Meanwhile, in the Norwegian context, the national origin was considered most relevant, as signified through flags on the wall. Pesch let us see how the conditions for ECE institutions are connected to a wider discourse on national and transnational practices and that symbols such as text, photos and flags can be seen as manifestations of cultural practices.

Children are exposed to symbols, learning material and role models in everyday life outside the fences of an ECE institution as well as inside. We can call these conditions discursive, as also suggested in the model of exploration as dialogical engagement. Next, I will present an example of the discursive conditions created by a global media event that changed a symbolic discourse, e.g. girls as passive and Latinos as inferior, as North American media stereotypes occasionally do.

Dora the Explorer is a show that is becoming global through the success of Nickelodeon, a children's cable network. ${ }^{9}$ Nickelodeon launched in 1977 as the first cable channel for children. It airs productions from 5:00 a.m. to 10:00 p.m. every day in 75 countries across the globe and is a powerful conditioning activity for children's formative development.

This show is a worldwide phenomenon seen in 74 countries. The main character is a girl in kindergarten, and each episode is built around a series of recurring events that occur during Dora's travels around the world. She carries a backpack and is accompanied by her talking anthropomorphic monkey named Boots. In each episode, Dora and Boots meet obstacles or puzzles that they have to solve. Dora seeks the viewers' help in solving the problems they face. Dora is an agentic, explorative child, challenging the ideal of the dutiful and well-behaved girl. She is also of Latino heritage, a heritage occasionally stereotypically presented in the media as uneducated and possessing limited language skills. The producers' view was that it is, in fact, expected that a child (i.e. a girl of Latino heritage) can be agentic in explorative ways.

Dora was considered a favourite among American children and was watched by 25 million viewers each month (Ryan, 2010, p. 56). Nickelodeon, as well as a range

\footnotetext{
${ }^{9}$ Dora the Explorer was a show at Nickelodeon airing from 2000-2014, but episodes are still repeated. The co-creators are Valerie Walsh and Chris Gifford (Larsen, 2014).
} 
of television companies, many parents and ECE institutions all over the world made Dora the Explorer a new ideal: the explorative agentic child—a girl. This show changed the rules of what sold in the market of preschool television (Ryan 2010). Dora the Explorer will serve as an example of how a television show, developed by former teachers and a television company, can change expectations and set a global model for an agentic, explorative child. This television program was the result of professional pedagogues trying to create programs for young children that opened the floor for exploration, and can be considered a media version of 'glocal' teachers. Thus, the discursive space was broadened through technology (Cvetkovic, Olson \& Olson, 2013).

An important aspect for pedagogy in early childhood will be the interest in new mediations (e.g. a new show targeting children, like Dora the Explorer) that present new ideals, heroes and antiheroes to children. The songs that are sung, the pictures presented, the narratives performed and other uses of media, toys and teaching equipment are all creating conditions for what the child may take up and explore (Schei \& Ødegaard, 2017; Cvetkovic et al. 2013; Mollenhauer, 1983). Institutions are structured by the knowledge that lies in the way things are done and structured: routines, habits, rhythm, pedagogical dramaturgy and the signs and symbols chosen.

\subsection{Meaning-Making and Participatory Space}

I will now turn to the most fundamental aspect of a human's social setting: that of meaning-making (Chen, 2001). Meaning-making aligns with cultural formation as persons draw meaning from, or add meaning to, events, activities and experiences. Meaning-making constitutes the explorative practice, however meaning- or sensemaking alone, is not enough.

In this sense, a person's meaning-making is a shared construct. Meaning coexists with a person's movement and involvement in the world. Cultural formation operates between the dynamic and continual interaction of the person's world and the wider discursive, material and relational reality. The essence of living is to make sense of one's experience of being (Chen, 2001, p. 322). Mikhail Bakhtin (1986, 1999) argued that meaning has a heteroglossic nature, as the social space is fundamentally interpersonal and enables both appropriation and transformation of the voice of the other. To live means to participate in dialogue: to ask questions, to give attention, to respond, to agree and so forth (Morson \& Emerson, 1990, p. 60).

Based on Bakhtin's work (1981, 1986), I developed a concept of participatory space (Ødegaard, 2007, pp. 95-99) to explore the process of narrative collaborative meaning-making and to argue that educational settings are not ideal. Even if a teacher is interested in children's worldviews and needs, the educational setting will always delimit what is possible for the teacher to follow up on later. A participatory space is a dynamic space. In educational institutions, power will be exercised for the simple reason that teachers will have a mandate, a call or a task. Even if the children are given rights to participate and influence their own lives, through laws and 
regulations, children's participation in educational settings will nevertheless be influenced by material and relational interaction with the teachers and other children. If an ECE institution is to foster a culture of exploration, this culture must have characteristics that encourage explorative action. Even if we succeed in finding some characteristics for the pedagogics of exploration and cultures of exploration, as I intend to do here, there will still be unpredictability (Ødegaard, 2011). How an activity will develop depends on the teacher, the children participating, the material and the cultural traditions. There will be emergences observed as movements, utterances and positioning the body in certain ways in certain places, but whether the new beginnings will progress to manifestations of narratives or activities depends on heteroglossic conditions. A participatory space is opened if, for example, shared narrative meaning-making is facilitated. Extended conversations, the places where activities unfold and the artefacts that are made available and used are shaping content and, thereby, cultures. In our case, we could say that when shared explorative activities begin, a participatory space is opened.

Also, Mörtenböck and Mooshammer (2011, p. 127) develop a similar concept of social space where, as a result of dialogue, there emerges a complex map of intensities whose distribution develops out of reciprocal points of contact. According to Birgitta Busch (2014), such a social space is not structured according to an overarching plan. She uses the Bakhtin concept of heteroglossia to propose a pedagogy with 'open spaces of potentialities, where the polyphony of voices, discourses and ways of speaking - all linked to different social-ideological worlds-is not kept out, but seen as a constitutive feature' (Busch, 2014, p. 38). She underlines that this Bakhtinian concept allows us to connect linguistic forms and historical social relations.

\subsection{The Relevance of 'Exploration' in Early Years Pedagogy in the 'Glocal' Landscape}

In this current era of globalisation, most early childhood policy- and curriculummaking processes are closely linked to their national challenges, professional and political discourses and the future-oriented global economies. Globally, we can see that ECE is increasingly seen as an arena for social mobility and lifelong learning (Field, 2006). Local teachers' practices are, however, personal and relational. The conditions for such practices are deeply ideological and political. What teachers can or cannot do and engage in with children, and what artefacts they choose or are expected to use with children, are entangled in structural, philosophical and ideological preconditions (Ødegaard, 2015, p. 44). Teachers will identify, understand and act upon those conditions. A local curriculum is both discursive and embodied and negotiated over time; it becomes entangled in the nation-state's political ideas and national historical events as well as the country's contemporary challenges and situations. Teachers live in semiotic and material landscapes that regulate and 
habituate the space and possibilities for teachers' practices and the awareness attached to them.

Professionals, families and children live as 'glocal' citizens, in the sense that technology is available for people on smaller or larger scales throughout the world. People using and participating through the internet, cell phones and digital play are engaging in activities that go beyond a country's territorial borders. The internet is a medium for globalisation. Critical voices argue that technology, media and the internet facilitate the dominance of Western culture and help eliminate the diversity of cultures and identities of people groups around the world. Science, technology, engineering and mathematics (STEM) education has, for many years, had strong advocacy globally, and the driving force has been the belief in the capacity of science, computers, engineering and mathematics to solve problems and create better societies. Criticism has also been raised towards the dichotomy often made between STEM and the arts. Wider perspectives, generic skills and both technical and more 'fuzzy' abilities are necessary if we are concerned about sustainable futures. The critical skills put forward are (a) to learn to learn and (b) to love learning, both skills that equip students to continue to follow their interests in life (p. 27). The ability to foster and liberate curiosity, creativity and exploration is central, whether it is called 'play' or 'learning'.

\subsection{Conclusion-Cultures of Exploration}

From the outline above, cultural formation processes are ever-present and continuous. Systems of structures and discourses (e.g. political, legal and economic) as well as systems of beliefs and ideologies govern practices-sometimes directly and other times indirectly, in subtle ways. Local practices are made up of social dynamics, cultural talk and manners. In this chapter, I have considered exploration as dialogical engagement, and pedagogical practices are seen as enacted in institutions inhabited by persons who interact in a myriad of emergent events. Institutions and pedagogical practices constitute - and, at the same time, are included in-social, political and symbolic conditions for explorative and cultural formative practices. I have presented a visualisation through a model of exploration as dialogical engagement, described by examples, and argued and discussed complex aspects of exploration. I have elaborated on the concept of exploration as well as similar and overlapping concepts. With inspiration from Escobar (2009), I have reconstructed and elaborated relevant dichotomies of a spectrum of notions that can characterise what exploration pedagogy is and what it is not. In this effort to conceptualise exploration and cultural formation, I can suggest some pedagogical principles and practices relevant for discussing exploration and what kinds of pedagogical cultures and practices might support exploration within the field of ECE.

Through examples and discussions above, I have shown how, for example, material and symbolic artefacts are made available and that material as well as conceptual artefacts play a crucial role in cultural formation. When people use artefacts 
that are made available in society at large, they engage in continuous processes, some of which might be explorative while others might not. Either way, cultural formation will be a continuous process of becoming, and certain practices and pedagogical content will be shaped.

Bakhtin's concepts (e.g. 1981) are considered useful because concepts in dialogism provide a conceptual system that can capture the complexity and dynamics often experienced in ECE practices. This chapter has, therefore, presented a model of exploration as dialogical engagement and outlined a set of crucial contemporary conditions for cultures of exploration. The attempt is anchored in arguments and examples for this new culture-sensitive thinking tool. Moreover, the model encourages a pedagogical idea that goes beyond a child- and teacher-centred approach by suggesting the dialogical engagement that requires dynamic communication and historical understandings. Children and teachers are explorative and sensitive to problems, relations, signs and sensations when working, playing and being together.

In order to move forward, I will emphasise the need to establish a committed leadership and involvement from stakeholders such as staff, children and families. In order to create pedagogical cultures of exploration, it could be promising to involve researchers and collaborators that can support the process of changing cultures and building knowledge and experience. Exploration is manifested in a complex matrix through body, movement, sensations, artefacts, materiality, symbols and discourses.

The model is called exploration as dialogical engagement to underline the demand for commitment by leaders and staff in building cultures of exploration. The characteristics of such pedagogical practices can be summarised as:

- Openness towards the world and children's and family's experiences and narratives

- Inquiry and curiosity towards multiple terms of knowledge, acknowledging emotional and performative as well as academic knowledge.

- Co-creation of meaning and improvisation in everyday activities

- Collaboration with stakeholders and partners

- Variation of cultural resources and topics

- Process-oriented with a high awareness of possible new beginnings and manifestations

Exploration as dialogical engagement could serve as a pedagogical thinking tool in pedagogies valuing and implementing culturally responsive practices and exploring practices and worldviews of sustainability. 


\section{References}

Alanen, L. (2009). Generational order. In J. Qvortrup, W. A. Corsaro, \& M. S. Honig (Eds.), The Palgrave handbook of childhood studies. London: Palgrave Macmillan.

Bakhtin, M. (1973). Problems of Dostoevsky's poetics (2nd ed.). Ann Arbor, MI: Ardis. (R. W. Rotsel, Trans.; Original work published 1929).

Bakhtin, M. (1981). Discourse in the novel (C. Emerson \& M. Holquist, Trans.). In M. Holquist (Ed.), The dialogic imagination (pp. 259-422). Austin, TX: University of Texas Press.

Bakhtin, M. M. (1986). The problem of the speech genre (V. W. McGee, Trans.). In Speech genres and other late essays (pp. 60-102). Austin, TX: University of Texas Press.

Bakhtin, M. M. (1999). The bildungsroman and its significance in the history of realism (toward a historical typology of the novel). In M. Holquist (Ed.), Speech genres and other late essays (pp. 10-59). Austin, TX: University of Texas Press.

Borgen, J. S., \& Ødegaard, E. E. (2015). Barnekultur som forskningsfelt - et interdisiplinært vitenskapelig emne. [Child Culture as a Research Field - an Interdisciplinary Topic]. Barn, 24(3-4), $1-16$.

Bostad, F., Brandist, C., Evensen, L. S., \& Faber, C. (2004). Bakhtinian perspectives on language and culture. New York: Palgrave Macmillan.

Braidotti, R., \& Bignall, S. (2019). Posthuman ecologies - Complexity and process after Deleuze. Lanham, MD: Rowman \& Littlefield.

Busch, B. (2014). Building on heteroglossia and heterogeneity: The experience of a multilingual classroom. In A. Blackledge \& A. Creese (Eds.), Heteroglossia as practice and pedagogy (pp. 21-40). New York: Springer.

Capra, F. (1982). The turning point. New York: Bantam New Age Book.

Chaiklin, S., \& Hedegaard, M. (2013). Cultural-historical theory and educational practice: Some considerations. CAPA, 24(1), 30-44.

Chaiklin, Z., \& Hedegaard, M. (2005). Radical-local teaching and learning. London: Århus University Press.

Chen, C. P. (2001). On exploring meanings: Combining humanistic and career psychology theories in counselling. Counselling Psychology Quarterly, 14(4), 317-330. https://doi. org/10.1080/09515070110091308

Comenius, J. A. (2012). Orbis Sensualium Pictus-A textbook. In J. Sokol (Ed.), Johannes Amos Comenius, Orbis Sensualium Pictus. Prague: Machart.

Cvetkovic, V., Olson, V., \& Olson, D. C. (2013). Portrayals of children in popular culture: Fleeting images. Lanham, MD: Rowman and Littlefield.

Escobar, O. (2009). The dialogic turn: Dialogue for deliberation. In-Spire Journal of Law, Politics and Societies, 4(2), 42-70.

Featherstone, M., Lash, S., \& Robertson, R. (1995). Global modernities. London: Sage Publications.

Field, J. (2006). Lifelong learning and the new educational order. Stoke-on-Trent, England: Trentham Books.

Fleer, M., \& Hedegaard, M. (2010). Children's development as participation in everyday practices across different institutions. Mind, Culture and Activity, 17(2), 149-178.

Fleer, M., Hedegaard, M., \& Tudge, J. (2009). World yearbook of education 2009: Childhood studies and the impact of globalization: Policies and practices at global and local levels. Routledge.

Fröbel, F. (2012 [1861]). The pedagogics of kindergarten. Memphis, TN: General Books LLC.

Fuller, B. (2007). Standardized childhood: The political and cultural struggle over early education. Stanford, CA: Stanford University Press.

Holquist, M. (1990). Dialogism. New York: Routledge.

Holquist, M. (2002). Dialogism: Bakhtin and his world. London: Routledge.

Ingold, T. (2011). The perception of the environment. Oxon: Routledge.

Ingold, T. (2018). The anthropology and/of education. New York: Routledge.

Kagan, S. (2013). Art and sustainability: Connecting patterns for a culture of sustainability. Bielefeld, Germany: Transcript Verlag. 
Kjørholt, A. T. (2004). Childhood as a social and symbolic space: Discourses on children as social participants in society. PhD Thesis. Trondheim: NTNU.

Larsen, B. K. (2014, September 1). Ultimate guide to Dora the Explorer. Retrieved from https:// lifestyle.howstuffworks.com/family/activities/how-dora-the-explorer-works2.htm

Lawrence, C. (2010). Historical key words - Explore. The Lancet, 375, 1.

Lee, H. (2018). Science for climate action. Opening speech at the 30th anniversary celebration for the Intergovernmental Panel on Climate Change (IPCC). Paris, 13 March 2018. Retrieved from http://ipcc.ch/pdf/press/P47Celebration30_HL.pdf

Linnell, P. (2009). Rethinking language, mind and world, dialogically; interaction and contextual of theories of human sense making. Charlotte, NC: Information Age Publishing.

Liu, Y., \& Liu, F. (2008). Building a harmonious society and ECE for a sustainable society. In I. Pramling Samuelsson \& Y. Kaga (Eds.), The contribution of early childhood education to sustainability. Paris: UNESCO.

Massey, D. (1991). A global sense of place. Marxism Today, Originally published June 1991. Retrieved from http://www.urbanlab.org/articles/Massey\%20global_sense_place.pdf

Massey, D. (2005). For space. London: Sage Publications.

Matusov, E. (2009). Journey into dialogic pedagogy. Hauppauge, NY: Nova Science.

Ministry of Education and Research. (2017). Framework plan for the content and tasks of Kindergartens. Bergen: Fagbokforlaget.

Mollenhauer, K. (1983). Vergessene Zusammenhänge: Über Kultur und Erziehung. Weinheim, Germany: Juventa-Verlag.

Morson, G. S., \& Emerson, C. (1990). Mikhail Bakhtin: Creation of a Prosaics. Stanford, CA: Stanford University Press.

Myrstad, A., \& Sverdrup, T. (2016). Første-fots-erfaringer gjennom vandring - de yngste barnas samspill med omgivelsene i barnehagen [First-foots experiences through wayfaring - the Youngest Children's interplay with environment in Kindergarten ]. I: Gupinar, T. Hernes, L. og Winger, N(eds). Blikk for barn [An Eye for Children]. Bergen, Norway: Fagbokforlaget.

Mörtenböck, P., \& Mooshammer, H. (Eds.). (2011). Space (re)solutions intervention and research in visual culture. Bielefeld: Transcript Verlag.

Nairn, K., Kraftl, P., \& Skelton, T. (2016). Space, place and environment. Singapore, Singapore: Springer.

Nesaria, A. J. (2015). Dialogism versus Monologism: A Bakhtinian approach to teaching. Procedia - Social and Behavioral Sciences, 205, 642-647.

Nolet, V. (2017). Quality education: Cultural competence and a sustainability worldview. Kappa Delta Pi Record, 53(4), 162-167. https://doi.org/10.1080/00228958.2017.1369276

Ødegaard, E. E. (2007). Narrative meaning-making in preschool. Thesis, Dr. Filosophie. Gothenburg: Acta Universitatis Gothenburgensis.

Ødegaard, E. E. (2011). On the track of cultural formative practice-A chronotopic reading of young children's co-narrative meaning making. In J. White \& M. Peters (Eds.), Bakhtinian Pedagogy: Opportunities and challenges for research, policy and practice in education across the globe (Series: Global studies of Education, nr. 7) (pp. 197-201). New York: Peter Laing.

Ødegaard, E. E. (2015). 'Glocality' in play: Efforts and dilemmas in changing the model of the teacher for the Norwegian national framework for kindergartens. Policy Futures in Education, $13(8), 42-59$.

Ødegaard, E. E. (2018a). 'Homo viator' - historiske forestillinger om 'verden' som sted og 'veiviseren' som pedagogisk ideal ['Homo viator' - Historical Ideas about the 'World' as Place and the 'Wayfarer as a Pedagogical Ideal]. In A. Myrstad, T. Sverdrup, \& M. Brit Helgesen (Eds.), Barn skaper sted - sted skaper barn [Children Shape Places - Places Shape Children] (pp. 101-118). Bergen, Norway: Fagbokforlaget.

Ødegaard, E. E. (2018b). Why and how early childhood educational research and practice are core keys to sustainable futures. Education day - Norwegian Education and Research delegation to China on the occasion of the Norwegian Minister of Research and Higher Education; 2018-0418. https://www.forskningsradet.no/servlet/Satellite?cid. 
Ødegaard, E. E., \& Marandon, A. (2018, May). Local weather events - exploring children's senseand place making. Paper presented at the Childhood \& Materiality Conference, Jyväskylä University, Finnish Society of Childhood research, Jyväskylä.

Pacini-Ketchabaw, V. (2017, June). Childhood studies in the Anthropocene. In proceedings of the International Conference and Graduate Student Workshop, University of Birmingham, Birmingham, England. Retrieved from http://commonworlds.net/childhood-studies-in-theanthropocene-international-conference-and-graduate-student-workshop-university-of-birmingham-uk-6th-7th-june-2017-call-for-conference-papers-and-call-f

Pesch, A. (2017). Creating space for multilingualism. A study of discursive conditions for ECECteachers' linguistic practice with multilingual children. $\mathrm{PhD}$ thesis, UiT - The Arctic University of Norway: https://munin.uit.no/bitstream/handle/10037/12202/thesis_entire.pdf?sequence=4 \&isAllowed $=\mathrm{y}$

Pettersen, G. O., Volden, M., \& Ødegaard, E. E. (2016). Chapter 6: Shared curiosity, technology and mathematics: Transitions between two and three dimensions. In S. Garvis \& N. Lemon (Eds.), Understanding digital technology and young children. London: Routledge.

Rogoff, B. (2003). The cultural nature of human development. New York: Oxford University Press Inc.

Ryan, E. L. (2010). Dora the explorer: Empowering preschoolers, girls, and Latinas. Journal of Broadcasting \& Electronic Media, 54(1), 54-68. https://doi.org/10.1080/08838150903550394

Samuelsson, I., Kultti, A., \& Pramling, N. (2018). Conceptualizing early childhood education and care for a global community: New directions in policy initiatives. In J. L. Roopnarine, J. E. Johnson, S. F. Quinn, \& M. M. Patte (Eds.), Handbook of international perspectives on early childhood education (pp. 423-429). New York: Routledge.

Sandvik, N. E. (2012). Rethinking the idea/ideal of pedagogical control. Contemporary Issues in Early Childhood, 13(3), 200-209.

Sawyer, K. R. (1997). Pretend play as improvisation - conversation in the preschool classroom. New Jersey: Lawrence Erlaub Associates Publishers.

Sawyer, R. K. (2011a). Explaining creativity: The science of human innovation. Oxford, England: Oxford University Press.

Sawyer, R. K. (Ed.). (2011b). Structure and improvisation in creative teaching. Cambridge, England: Cambridge University Press.

Schei, T. B., \& Ødegaard, E. E. (2017). Stories of style. Exploring teachers' self-staging with musical artefacts. In S. Garvis \& N. Pramling (Eds.), Exploring lived experiences: Narratives and early childhood (pp. 59-69). London, England: Routledge.

Schoggen, P., \& Schoggen, M. (1985). Play, exploration and density. In J. Wolvet \& W. Vliet (Eds.), Habitats for children - The impact of density (pp. 77-95). Hillsdale, NJ: Lawrence Erlbaum Associates.

Shephard, D. (2013). Dialogism. In P. Hühn, J. Pier, W. Schmid, \& J. Schönert (Eds.), The living handbook of narratology (LHN). Retrieved from http://www.lhn.uni-hamburg.de/article/ dialogism

Spyros, S. (2017). Time to decentre childhood? Childhood, 24(4), 433-437. https://doi. org/10.1177/0907568217725936

Steffen, W., Grinevald, J., Crutzen, P., \& McNeill, J. (2011). The Anthropocene: Conceptual and historical perspectives. Philosophical Transaction of the Royal Society A, 369, 842-867. https://doi.org/10.1098/rsta.2010.0327

Tobin, J., Hsueh, Y., \& Karasawa, M. (2009). Preschool in three cultures revisited: China, Japan, and the United States. Chicago, IL: Chicago University Press.

ULIN. (2007). United league of indigenous nations the treaty. Retrieved from http://www.indigenousnationstreaty.org/.

Uprichard, E. (2008). Children as beings and Becomings: Children, childhood, and temporality. Children and Society, 22(4), 303-313.

White, E. J. (2016). Introducing dialogic pedagogy - Provocations for the early years. New York: Routledge. 
Open Access This chapter is licensed under the terms of the Creative Commons Attribution 4.0 International License (http://creativecommons.org/licenses/by/4.0/), which permits use, sharing, adaptation, distribution and reproduction in any medium or format, as long as you give appropriate credit to the original author(s) and the source, provide a link to the Creative Commons licence and indicate if changes were made.

The images or other third party material in this chapter are included in the chapter's Creative Commons licence, unless indicated otherwise in a credit line to the material. If material is not included in the chapter's Creative Commons licence and your intended use is not permitted by statutory regulation or exceeds the permitted use, you will need to obtain permission directly from the copyright holder. 